Scrvicio de Ototrinolaringologia

del Hospital Arriarán.

Jiefe: Dr. M. Parada.

\title{
RINITIS PSEUDOMEMBRANOSAS NO DIFTERICAS
}

\author{
Por a Dr. AUGUSTO LATORRE AGUERO
}

La rinitis pseudomembranosa diftérica es una afección muy común en la práctica infantil y sus caracteres cínicos son ampliamente conocicos por el médico padirter. En efec to, se trata, por lo general, de un coriza unilateral. mucosanguinolento, con epistaxis a repetición, erosiones del vestibulo nasal $y$ ala de ja nariz, tumefacción dé labio superior $y$, a veces, adenopatías cervicales voluminosas. Al examen rinoscópico se encuentra en la fosa nasal, la mucosa cubierta de pseudomembranas adherentas que sangran a la menor tentativa de desprenderlas.

Tal es el cuadro clinico corriente de la difteria nasal. Su diagnóstico es. por lo tanto, re'ativamente fácil para el pediatra o para el otorrinólogo. en la gran mayoría de los casos; pero, sólo el Laboratorio nos puede asegurar este diagnórtico, revelando la presencia de bacilos de Loeffler en la secreción nasal.

Sin embargo, últimamente me ha tocado observar en varias oportunidades, a niños que presentaban una afección nasal con las caracteristicas clínicas ya mencionadas, que habían sido examinados por médicos pediatras y por otorrinólogos, y a los cuales se les hizo colocar, de inmediato, una fuerte dosis de suero antidiftérico, sin espetrar el resultado del examen bacterióógico de la secreción nasal e incluso. en al- 
gunos casos, sin haberse tomado una muestra de esta secreción para investigar la existencia de bacilos de Loeffler. $O$ sea, estos colegas ante una tinitis pseudomembranosa, procedieron con el mismo criterio con que habrian actuado ante una angina pseudomembranosa: hicieron colocar suero antidiftérico sin esperar la confirmación del diagnóstico de difleria por el Laboratorio.

Este proceder es lógico tratándose de la faringe, pero es muy discutible en lo que se refiere a las fosas nasales

Las anginas pseudomembranosas de la infancia, prázticamentel, son siempre de origen diftérico. Por otra parte, la difteria faríngea es una enfermedad grave que puede producir. a veces en pocas horas, graves complicaciones tóxicas o de vecindad; de aquí la indicación de empletar la sueroterapia a altas dosis, rápidamente y sin esperar el resultado del examen bacteriológico de la secreción, ante la sospecha de una difteria de la faringet.

En cambio, no sucede lo mismo con las rinitis pseudomembranosas. entre las cuales hay muchas que no son diftéricas y en que el examen de la secreción nasal revela la existencia de otros gérmenes tales como estreptococo. estafilococos, pneumococos, etc.

Luego en presencia de una rinitis pseudomembranosa debemos cerciorarnos primero, recurriendo al Laboratorio, si se trata de una difteria nasal, antes de indicar la sueroterapia, a fin de evitar los inconvenientes derivados cel uso innecesario del suero (creación de un estado de anafilaxia, molestias propias de la enfermedad del suero. etc.).

Aun en el caso de que se trate de una difteria nasal, el hecho de esperar 24 horas para precisar el diagnóstico, no encierra en la práctica, ningún peligro para el paciente: porque, como es sabido, la difteria nasal no tiene la gravedaj de la difteria de la faringe; menos aún ei nuestro pais ton donde la difteria, en general, es muy benígna, compatada con otros países como el Uruguay o la Argentina. La mayor part de las veces la difteria nasal se presenta, entre nosotros. como una afección de curso crónico que puede durar varias semanas y sin que se presenten complicaciones tóxicas o de vecindad. El porqué de esta relativa benignidad de la difteria nasal, no ha sido aún claramente explicado. Se ha dicho, entre otras cosas, que la mucosa nasal presentatía una mayor tesistencia al bacilo de Lóeffler que la mucosa de la faringe y que, a la larga, éste sería destruido por la secreción nasal. 
Voy a leerles, a continuación, algunas observaciones de rinitis pseudomembranosas no diftéricas. recogidas últimamente en nuestro servicio del Hospital Arriarán:

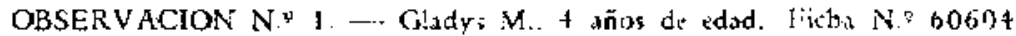
dar Hospitat Arriatán.

Examicada en julio del presente uño.

Antecedentes hereditarios y personales: Sin importancin.

Enfermedad actual: Desde bace 15 diss prexenta obstrucción nasal: secteción espesa, macopurulenta y sanguinolenta por la fosa nasal kncha: epistuxis a repetición, erosiones del vestibulo nasal y ligera cumefaceión del latrio superior.

Examen: Niäa pálida, delgada, afebrit. Al examen rinosópico encontcimos en la fosa nasal derecha, secteción psendomembranosa, odherente $y$ qua sangra fáciltmente al tacto. Faringe notmal. Adenopatís volnminosas en ath bas regiones submaxilares.

Se tema ura muesta de la secreción nasal y se envia al Laboratorio pard investigar la presencia de bacilos de Loeffler. El resuitado del examen es negativo: no habo desarrollo de batilos diftíticos. sino de estreptococos hemoliícos. El examen de uga nueta muestra da idéncisos resultados.

La niña sanó alrededor de 10 días despits con un tratamiento locai a base de instilaciones de aceite gomenoludo al $5 \%$ y tocaciones de ritrato de plata $\therefore 2 \%$.

OBSERVACION N, $2, \rightarrow$ Roberto O., 8 años de edad. Ficha N. 76322 de1 Hospital Artiarán.

Examinado en julio del presente año.

Antecedentes hereditarios $Y$,personales: Sin importancia,

Enfermedad actual: Desce hace cerea de tres semanas tiene obstructión assal, secreción espesa nutosanguinolenta por la fos nusat- derecha $y$ erosiones del vestibrio nasal y labio superior.

Examen: Buen estado genetal. Affebril. Furinge nada de especial. At axamen rinascópieo presenta en la fosa nasa! derecba, tumefaccióa de la macosa $Y$ secreción psecdomembranosa que sangra fascilmente al tratax de desprendeda.

El examen bucteriológico de la secreción, repetido en fos ocasiones. sólo reveló la presencia de estreptococo bemolítico.

Este niño sanó de su afección nasat, desputs de varios dias de tratamieato (instifisciones gomenoladas, pomada de Neisset, etc.) y sin presentar ningaDa complication.

OBSERVACION N, 3. - Mantel M. Edad: 16 meses, Fijcha N.9 80059 Llet Hoopital Arriaiono.

Examinado en julio ded prearate ato.

Antecedentes herediturios $y$ pesonzles: Sin importancia. 
Enfermedad actoal: Desde hace cerea de dos temanas tiente coriza macosacgaisolenta bilatetal, obstracción nasal y crosiones de las alas de 1 a nariz y hirio superior.

Examen: Buen estado geneta!. Afobril. A lis rinoscopia antcrior se en: coentea en ambas fosas nasales. sectrión purulenta espesa, muy adberente. La macosa esté tumefacta y sangta con mutiz facilidad. Faringe ada de espotial.

El cultivo de la secrecion aasal dió solumenti desarrollo de pneumococos

Como podemos ver por la lecțura de las observaciones anteriores, el cuadro clínico de las rinitis pseudomembranosas no diftéricas, es idéntico al de las diftéricas. Entre estas dos afecciones el diagnóstico clinico es imposible. En ambas hay obstrucción nasal, escurrimiento de serosidad sanguinolenta que provoca escoriaciones del ala de la nariz y labio superior; la fosa nasal set presenta ocupada por una pseudomembrana fibrinosa, adherente, y por debajo de ella la mucosa está tumefacta y sangrante. El examen bacteriológico de la secreción es lo que hace el diagrióstico, revelando la presencia de bacilos de Loeffler, si se trata de una difteria nasal. o su ausencia y desarrollo de otros gérmenes, en las rinitis pseudomembranosas no diftéticas.

Las rinitis pseudomembranosas no diftéricas fueron perfectamente conocidas por los antiguos. En 1906, por ejemplo. Bar (citado por Bertoin) hizo una comunicación sobre este tema a la Sociedad Francesa de Laringología. en la sual exponía las dos doctrinas más aceptadas para explicar la etiologia de estas rinitis: la doctrina anicista y la doctrina dualista.

Los partidarios de la doctrina unicista sostenian que tindas las rinitis pseudomembranosas eran diftéricas y que el hecho de no encontrar el bacilo de Loeffler en la mucoka nasal; podía deberse a que-la mucosa nasal, muy resistente a este bacilo. secretaria una antitoxina que lo destruicia al cabo de cierto tiempo.

Esta doctrina es evidentemente crrónea. Ásí como en la faringe y laringe pueden hater pseudomembranas no diftéricas, no hay razón para que no las haya también en las fosas nasales. Por esto la doctrina dualista es la aceptada actualmenta Según ella, las rinitis pseudomembranosas pueden ser diftéricas o no diftéricas. Las diftéricas son las más frecuentes en la práctica. Las no diftéricas se encontratian en el 20 a $25 \%$ de los casos y en ellas los exámentes repetidos de ta secreción nasal, no dá nunca desateotlo de bacilos de loeffler 
sino de otros gérmenes, tales como estreptococo hemolitico, estafilococos, pneumococos, etc.

Luego ante una rinitis pseudomembranosa debemos investigar cuidadosamente su etiología y no iniciar a ciegas la sueroterapia antidiftérica. Como dijimos anteriormente, ante un cuadro sospechoso de difteria, no debemos proceder en las fosas nasales con el mismo criterio que en la faringe.

Estas rinitis pseudomembranosas no diftéricas son, por 10 general, muy rebeldes al tratamiento y pueden prolongarse varias semanas. Nosotros hemos ensayado en ellas, sin ningún resultado, las sulfamidas, tanto por vía oral como en instilaciones locales bajo la forma de sulfatiazol sódico en solución al $5 \%$. Las instilaciones aceitosas (gomenoladas o mentoladasi y las curaciones repetidas con soluciones astringentes (nitrato de plata al $2 \%$, cloruro de zinc al $1 \%$ ) pareceri set el mejor tratamiento.

\section{BIBLIOGRAFIA}

BERTOIN R. - "Rinitis pseudomembrineuses non diphlésiques. Arel. Int.

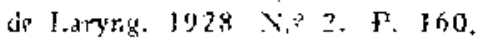

